\title{
Hypoxemia predicts death from severe falciparum malaria among children under 5 years of age in Nigeria: the need for pulse oximetry in case management
}

\author{
Orimadegun Adebola ${ }^{1}$, Ogunbosi Babatunde ${ }^{2}$, Orimadegun Bose ${ }^{3}$
}

1. Institute of Child Health College of Medicine, University of Ibadan, Nigeria

2. Department of Paediatrics, College of Medicine, University of Ibadan, Nigeria

3. Department of Chemical Pathology, College of Medicine, University of Ibadan, Nigeria

\begin{abstract}
Background: Oxygen saturation is a good marker for disease severity in emergency care. However, studies have not considered its use in identifying individuals infected with Plasmodium falciparum at risk of deaths.

Objective: To investigate the prevalence and predictive value of hypoxaemia for deaths in under- $5 \mathrm{~s}$ with severe falciparum malaria infection.

Methods: Oxygen saturation was prospectively measured alongside other indicators of disease severity in 369 under-5s admitted to a tertiary hospital in Nigeria. Participants were children in whom falciparum malaria parasitaemia was confirmed with blood film microscopy in the presence of any of the World Health Organization-defined life-threatening features for malaria.

Results: Overall mortality rate was $8.1 \%$. Of the 16 indicators of the disease severity assessed, hypoxaemia $(\mathrm{OR}=7.54$; $95 \% \mathrm{CI}=2.80,20.29)$, co-morbidity with pneumonia $(\mathrm{OR}=19.27$; $95 \% \mathrm{CI}=2.87,29.59)$, metabolic acidosis $(\mathrm{OR}=6.21 ; 95 \%$ $\mathrm{CI}=2.21,17.47)$ and hypoglycaemia $(\mathrm{OR}=19.71 ; 95 \% \mathrm{CI}=2.61,25.47)$ were independent predictors of death. Cerebral malaria, male gender, wasting, hypokalaemia, hyponatriaemia, azotaemia and renal impairment were significantly associated with death in univariate analysis but not logistic regression model.

Conclusions: Hypoxaemia predicts deaths in Nigerian children with severe malaria, irrespective of other features. Efforts should always be made to measure oxygen saturation as part of the treatments for severe malaria in children.
\end{abstract}

Keywords: Severe malaria, Under-5 mortality, Oxygen saturation, Hypoxaemia

African Health Sciences 2014; 14(2):397-407

DOI: http://dx.doi.org/10.4314/ahs.v14i2.16

\section{Introduction}

Malaria is a common cause of childhood illness in subSaharan Africa, though recent reports showed that malaria-related deaths have decreased by as much as $30 \%$ between 2004 and $2010^{1,2}$. The disease remains one of the leading causes of under- 5 mortality in subSaharan Africa ${ }^{3,4}$. The magnitude of deaths from acute falciparum malaria remains an issue of public health concern and it is often the main reason for paediatric hospital admissions in many African countries. For instance, malaria is responsible for $30 \%$ childhood

\section{Corresponding author: \\ Adebola E. Orimadegun \\ Institute of Child Health, College of \\ Medicine, \\ University of Ibadan, Nigeria \\ Mobile phone: +2348058266882 \\ E-mail: beorimadegun@yahoo.com}

mortality, $11 \%$ maternal mortality and more than $60 \%$ outpatient visits in Nigeria ${ }^{5}$.

Major strategies aimed at the control and reduction of mortality from malaria includes case management with antimalarial drugs and ancillary treatments such as optimal fluid and oxygen therapy. Although children suffering from falciparum malaria infection often present with known symptoms and signs of hypoxaemia such as tachypnoea, altered level of consciousness and chest wall in-drawing, to whom oxygen should be administered is still an open question ${ }^{6-8}$. It is often difficult for physicians working in resource poor settings, where facilities for objective detection of hypoxaemia, to decide whether oxygen needs to be administered to children with acute falciparum malaria. This difficulty centres on the fact that symptoms and signs indicative of hypoxaemia do not sufficiently predict the need for oxygen therapy ${ }^{9}$. Moreover, facilities to accurately assess the level of haemoglobin desaturation such as blood gas analysers are not available in many health facilities. Physicians practicing in such resource-poor settings 
often depend on clinical signs to decide on the need for oxygen therapy. Consequently, many of the children who should be given oxygen are missed and some of those who do not need it are often given.

Published data on the burden of hypoxaemia could guide treatment policy, but only a few studies have reported hypoxaemia among children with acute malaria infection and there is no evidence of beneficial effect of empirical oxygen administration. More so, conducting a clinical trial of this nature would be unethical. Previous studies have reported prevalence ranging from $2.9 \%$ to $17 \% \%^{10-14}$. All these studies were not focused on the role of oxygen saturation in malarial-related deaths. So far, the contribution of hypoxaemia to deaths among children suffering from malaria is not clear from published literature.

Assessing the level of oxygen saturation among acutely ill children has clinical and public health relevance. A study on the effects of hypoxaemia in acute falciparum malaria illnesses may reflect the magnitude of cases with coexisting cardiopulmonary compromise and those in whom accompanying subtle hypoxic organ injury may have been unrecognised ${ }^{14}$. Even a relatively low prevalence of hypoxaemia in a common disease like malaria may translate to a considerably large burden in countries with large children population like Nigeria. According to the 2012 revision of the "World Population Prospects", the proportion of children below the age of 15 years was $44.0 \%$ of the estimated total population of $159,708,000$ in $2010^{15}$. Furthermore, the association between hypoxaemia and death underscores the need for its early recognition and the potential benefit of prompt and appropriate oxygen therapy. Nonetheless, many health workers in Africa may not be sufficiently aware of the need to screen for hypoxaemia ${ }^{16}$. Therefore, this study was carried out to investigate the prevalence and predictive value of hypoxaemia for deaths due to acute falciparum malaria in children.

\section{Methods}

\section{Study design and setting}

This prospective cross-sectional study was carried out at the children emergency unit of the University College Hospital (UCH) Ibadan, a tertiary health facility located in the south-west of Nigeria over an 18-month period (May 2010 - October 2011). All children needing oxygen at the centre during the study period were given at subsidised costs paid by the caregivers. The children emergency unit has a side-room laboratory where basic tests such as urinalysis, microscopy and haematocrit determination were carried out.

\section{Study patients and recruitment procedures}

During the study period, 369 of 381 febrile (axillary temperature $>37.5$ degree Celsius) children aged 6 to 59 months with a positive Plasmodium falciparum on blood film for microscopy and features of the World Health Organization (WHO) case definition for severe malaria ${ }^{17}$ were recruited consecutively. All children presenting in the emergency unit had pulse oximetry upon arrival and they were clinically examined by paediatric resident doctors and supervising consultant paediatrician. Those who had clinical signs suggestive of cardiac defect and those whose parents refused consent were excluded from the study.

\section{Data collection procedures}

Doctors and a research assistant working in the emergency unit independently recorded signs and symptoms at the time of admission into a structured questionnaire. The children emergency unit was supplied with True colour OLED fingertip oximeters, Models: CMS50QA, CMS50QB, CMS50EW and CMS60CW (Contec ${ }^{\mathrm{TM}}$, China) by the researchers. The doctors and the research assistant were trained on the use and care of pulse oximeters before the study and retrained at 6-month intervals. A laminated protocol for the use of pulse oximetry and management of severe malaria were provided. The questionnaire used for data collection was attached to the regular hospital case note at the point of registration on arrival at hospital for all patients and only removed at discharge.

\section{Measurements and definitions of variables}

Arterial oxygen saturation was measured with an appropriately sized oxygen sensor placed on the right toe or finger while the patients breathe room air. Hypoxaemia was defined as an arterial oxygen saturation $\left(\mathrm{SpO}_{2}\right)<90 \% 0^{9,18} . \quad \mathrm{SpO}_{2}$ measurement was recorded after 3 minutes of stable observation. If the $\mathrm{SpO}_{2}$ was $90 \%$ or less, the child was immediately given oxygen via nasal or nasopharyngeal route. Manifestations of severe malaria considered in this study included: coma, defined by a Blantyre Coma Scale (BCS) score $\leq 2$ for children less than 2 years of age or a Glasgow Coma Scale (GCS) score $\leq 9$ for older children; prostration, defined as the inability to sit unsupported or the inability to drink or breast-feed in younger children; convulsions with a duration longer than 30 minutes or a frequency of 2 or more in the 24 hours preceding 
admission; severe respiratory distress, defined as flaring of alar nasi, subcostal or lower chest in-drawing, or use of accessory muscles, severe tachypnoea, or deep breathing; hypoglycaemia, defined as blood glucose $<3 \mathrm{mmol} / \mathrm{L}$ or clinical improvement in the level of consciousness immediately after administration of $10 \%$ dextrose; severe anaemia, defined as haematocrit of less than $15 \%$; passing of dark or "coca-cola" coloured urine; clinically demonstrable jaundice; hyperparasitaemia, defined as asexual parasitaemia greater than 250,000 per microlitre of blood and renal impairment was defined as urine output $<12 \mathrm{ml} / \mathrm{kg} / 24$ hours and a serum creatinine $>265 \mu \mathrm{mol} / 1(>3.0 \mathrm{mg} / \mathrm{dl})$ despite adequate volume repletion. Pneumonia was defined by the presence of cough, fast breathing and chest wall in-drawing in a child with clinical auscultatory signs and they all had chest $x$-ray for confirmation ${ }^{19,20}$. Children who were unconscious, presented with convulsions or were critically ill were referred for radiography after their condition stabilized.

\section{Laboratory procedures}

Packed cell volume was determined using the capillary method and spinning in a Hawksley micro-haematocrit centrifuge at $11,000 \mathrm{x} \mathrm{g}$ for $5 \mathrm{~min}$ at room temperature. The packed cell volume was then read with a haematocrit reader. Thick and thin films were made on the same slide for each patient. The thin film was fixed with methanol immediately and the slide was allowed to dry, then flooded with Giemsa already diluted 1 in 10 with phosphate buffer, $\mathrm{pH}$ 7.2. The stain was washed off with distilled water, after allowing it to stand for about $10 \mathrm{~min}$, and then air-dried. The stained films were then examined microscopically for malaria parasites using a x100 objective (oil immersion) and x10 eye piece lenses i.e. total magnification of $\mathrm{x} 1,000$. The parasites were counted against 200 white blood cells (WBC) and parasite density was calculated for each patient based on an assumed total WBC of $8000 / \mu \mathrm{L}$ of blood. Other laboratory tests were carried out in the hospital central laboratory using the automated techniques.

\section{Patient treatments}

All the children received standard care according to the Nigeria and WHO treatments guidelines ${ }^{5,21}$. These included: administration of intravenous artesunate at $2.4 \mathrm{mg} / \mathrm{kg}$ body weight stat, repeated after 12 hours and 24 hours, then once daily for 6 days. However, once any child regained consciousness and could take orally, parenteral therapy was discontinued and a full course of artemether-lumefantrine was administered. All patients with $\mathrm{SpO}_{2}<90 \%$ were given oxygen via nasal or nasopharyngeal tubes, other ancillary treatments were given according to standard protocol.

\section{Data management and analysis plan}

Data were entered and analysed using SPSS 17.0 statistical software (SPSS Inc. USA). Comparisons were made among three main categories of severe malaria, namely; cerebral malaria (CM), severe malarial anaemia (SMA) and other features of malaria (OFM). The main dependent variable of interest was outcome of severe malaria (defined as died or survived). Independent variables included: hypoxaemia (defined as $\mathrm{SpO}_{2}<90 \%$ ), clinical signs, age, gender, laboratory findings including blood sugar, parasite counts and plasma electrolytes and co-morbidities. Chi-square test was utilised for crosstabulations between the dependent and independent categorical variables, associations between continuous independent variables and the dependent variable was by one-way ANOVA. Logistic regression was used to determine the association between outcomes and independent variables. Ten of the fifteen variables examined in univariate analysis were significantly associated with death and they were included in the logistic regression model. $P$ values less than 0.05 were considered statistically significant for all analyses.

\section{Ethical considerations}

Participation in the study was completely voluntary and based on informed consent. Caregivers were made to understand that they were free to withdraw their child/ ward at any time, and that they would continue to receive the standard care for the disease according to protocol. The results of pulse oximetry in this study were made available to the attending doctors. The study protocol was reviewed and approved by the Oyo State Ethical Review Committee, State Ministry of Health, State Secretariat, Ibadan.

\section{Results \\ Characteristics of study patients}

The study patients comprised $221(59.9 \%)$ males and $148(40.1 \%)$ females. Specific life-threatening features found among these children were coma/cerebral malaria, CM ( $\mathrm{n}=81 ; 22.0 \%$ ), severe anaemia, SMA $(\mathrm{n}=201 ; 54.5 \%)$ and others features, OFM ( $\mathrm{n}=87$; $23.6 \%$ ) including multiple convulsions ( $\mathrm{n}=47 ; 12.7 \%$ ), metabolic acidosis with or without respiratory distress (n $=8 ; 2.2 \%)$, prostration $(\mathrm{n}=12 ; 3.3 \%)$, haemoglobinuria 
$(\mathrm{n}=10 ; 2.7 \%)$ and high output diarrhoea $(\mathrm{n}=10 ;$ months while that of severe malarialanaemia and others $2.7 \%$ ). The modal age for cerebral malaria was $48-59$ features was $24-35$ months (Figure I).

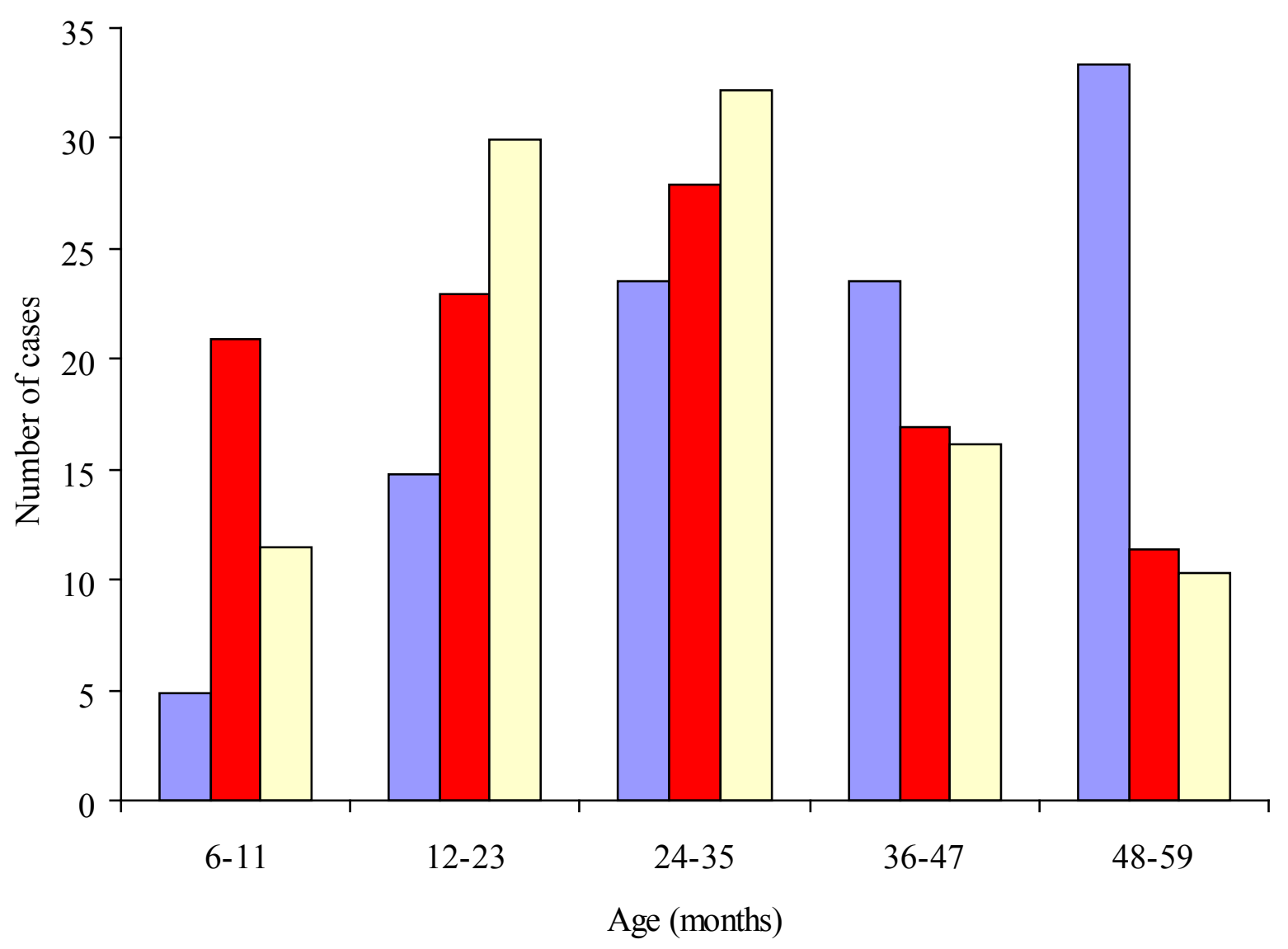

$\square$ Cerebral malaria $\square$ Severe malarial anaemia $\square$ Others

Mean ages of the different categories of severe malaria varied significantly with the children in the cerebral malaria group being higher than the other two groups (Table 1). 


\begin{tabular}{lccccc}
\hline & $\begin{array}{c}\text { All patients } \\
(\mathrm{n}=369)\end{array}$ & $\begin{array}{c}\text { Cerebral malaria } \\
(\mathrm{n}=81)\end{array}$ & $\begin{array}{c}\text { Severe malarial } \\
\text { anaemia } \\
(\mathrm{n}=201)\end{array}$ & $\begin{array}{c}\text { Other forms } \\
\text { of } \\
\text { severe malaria } \\
(\mathrm{n}=87)\end{array}$ & $\mathrm{P}$ \\
\hline $\begin{array}{l}\text { Sex } \\
\text { Male }\end{array}$ & $221(100.0)$ & $49(22.2)$ & $117(52.9)$ & $55(24.9)$ & 0.723 \\
$\quad$ Female & $148(100.0)$ & $32(21.6)$ & $84(56.8)$ & $32(21.6)$ & \\
Mean age (months) & $28.2 \pm 14.3$ & $35.7 \pm 13.8$ & $25.8 \pm 14.1$ & $26.5 \pm 12.9$ & $<0.001$ \\
Mean weight (kg) & $10.9 \pm 3.3$ & $12.7 \pm 3.3$ & $10.3 \pm 3.1$ & $10.9 \pm 3.0$ & $<0.001$ \\
Weight-for-height & $140(37.9)$ & $48(59.3)$ & $68(33.8)$ & $24(27.6)$ & $<0.001$ \\
$\quad$ Z-score $<2.0$ & $229(62.1)$ & $33(40.7)$ & $133(66.2)$ & $63(72.4)$ & \\
Z-score $>2.0$ & $6(1.6)$ & $4(4.9)$ & $2(1.0)$ & $0(0.0)$ & - \\
Bacteriaemia & $6(1.6)$ & $0(0.0)$ & $2(1.0)$ & $4(4.6)$ & - \\
Pneumonia & & & & \\
\hline
\end{tabular}

Post hoc analysis revealed that mean age of cerebral malaria patients were significantly higher than SMA and other features by 9.8 months $(\mathrm{p}<0.001)$ and 9.1 months $(\mathrm{p}<0.001)$ respectively while the difference between mean ages of severe malarial anaemia and those with other features was not significant. The distribution of patients by gender was also as shown in Table 1. Overall, $37.9 \%$ of the patients were wasted (weight-forheight $z$-score $<2.0$ ). The cerebral malaria group had the highest prevalence of wasting, followed by malarial anaemia $(33.8 \%)$ and those with other features (27.6\%). Pneumonia was also detected in 2 and 4 cases of SMA and OFM respectively.

\section{Laboratory and pulse oximetry findings}

The comparisons of the main laboratory findings among the three categories of severe malaria patients were as shown in Table 2. 
Table 2: Main laboratory findings among children with falciparum malaria

\begin{tabular}{|c|c|c|c|c|}
\hline & $\begin{array}{l}\text { Cerebral malaria } \\
(\mathrm{n}=81)\end{array}$ & $\begin{array}{l}\text { Severe malarial } \\
\text { anaemia } \\
(\mathrm{n}=201)\end{array}$ & $\begin{array}{l}\text { Other features of } \\
\text { severe malaria } \\
(\mathrm{n}=87)\end{array}$ & $\mathrm{P}$ \\
\hline \multicolumn{5}{|c|}{ Parasite counts (per $\mu \mathrm{L})$} \\
\hline Min - Max & $607-298,606$ & $124-158,900$ & $985-280,780$ & \\
\hline \multirow[t]{2}{*}{ Geometric Mean } & 138,234 & $119,306 \pm 10,340$ & 136,300 & $0.080 *$ \\
\hline \multirow{2}{*}{\multicolumn{5}{|c|}{ Plasma Urea (mmol/L) }} \\
\hline & & & & \\
\hline Min - Max & $4.8-13.6$ & $3.6-16.0$ & $3.6-15.9$ & \\
\hline Mean & $6.4 \pm 2.2$ & $6.5 \pm 2.4$ & $6.2 . \pm 3.0$ & 0.649 \\
\hline \multicolumn{5}{|c|}{ Plasma Creatinine $(\mathrm{mmol} / \mathrm{L})$} \\
\hline Min - Max & $17.7-66.1$ & $18.8-78.4$ & $18.8-78.4$ & \\
\hline Mean & $44.2 \pm 8.8$ & $43.0 \pm 17.7$ & $41.9 \pm 13.0$ & 0.615 \\
\hline \multicolumn{5}{|l|}{$(\mathrm{mmol} / \mathrm{L})$} \\
\hline Min - Max & $10.0-28.0$ & $10.0-30.0$ & $11.0-26.0$ & \\
\hline Mean & $17.4 \pm 3.9$ & $18.3 \pm 4.4$ & $18.3 \pm 4.1$ & 0.129 \\
\hline \multicolumn{5}{|c|}{ Plasma glucose $(\mathrm{mmol} / \mathrm{L})$} \\
\hline Min - Max & $2.5-14.2$ & $1.4-12.1$ & $2.0-16.7$ & \\
\hline Mean & $6.6 \pm 2.3$ & $5.9 \pm 2.3$ & $4.5 \pm 2.4$ & 0.013 \\
\hline
\end{tabular}

*Mann-Whitney U test, ${ }^{+}$Student $t$ test

Normal values: $\quad$ Urea $=5-16 \mathrm{mmol} / \mathrm{L}$

Creatinine $=<88.8 \mathrm{mmol} / \mathrm{L}$

The mean values of parasite counts, plasma urea, creatinine and bicarbonate of the three categories of severe malaria were not significantly different. Conversely, there were significant variation in the mean plasma glucose; it was highest in the CM $(6.6 \pm 2.3$ $\mathrm{mmol} / \mathrm{L})$, followed by the SMA $(5.9 \pm 2.3 \mathrm{mmol} / \mathrm{L})$ and OFM $(4.5 \pm 2.4 \mathrm{mmol} / \mathrm{L})$ had the lowest. Overall, prevalence of hypoxaemia in children with severe falciparum malaria was $29.8 \%$. Prevalence of hypoxaemia significantly varied among the groups of severe malaria cases as shown in Figure 2, with 28 out of 81 (34.6\%) CM, 68 out of $201(33.8 \%)$ SMA and 14 out of 87 $(16.1 \%)$ OFM cases being hypoxaemic $(p=0.006)$. 


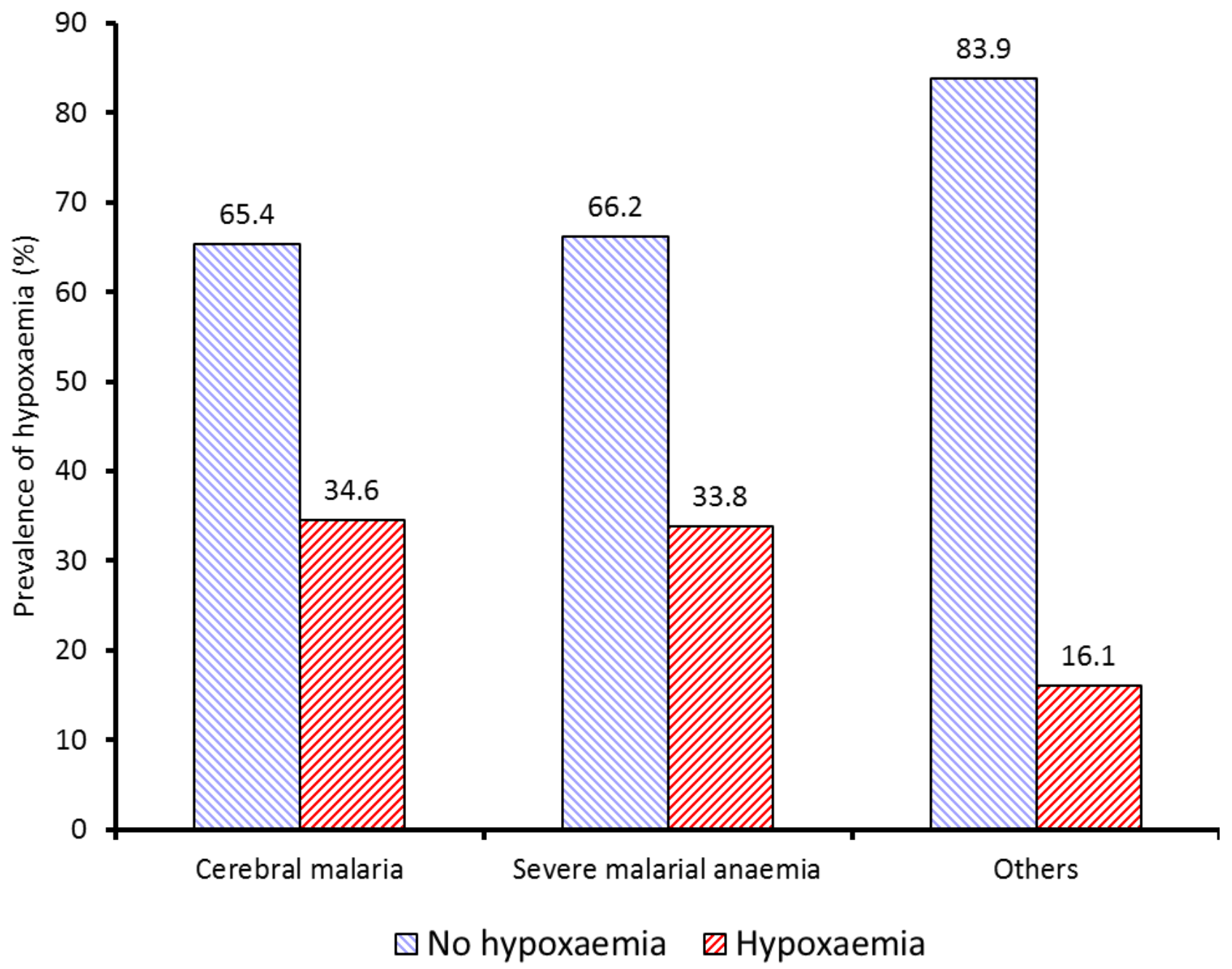

Figure 2: Prevalence of hypoxaemia by severe malaria category

Predictors of mortality among severe malaria patients

The overall mortality rate among children with severe malaria in this study was $8.1 \%$. These consisted of 12 $(14.8 \%)$ of the $81 \mathrm{CM}, 8(4.0 \%)$ of $201 \mathrm{SMA}$ compared with $10(11.5 \%)$ of 87 OFM groups. Table 3 shows the case fatality rate in patients with selected known prognostic indicators for severe malaria as well as odd ratios obtained from univariate analyses and multivariate logistic regression model. 


\begin{tabular}{lcccc}
\hline & $\begin{array}{c}\text { No. of } \\
\text { patients }\end{array}$ & $\begin{array}{c}\text { Case } \\
\text { fatality } \\
(\%)\end{array}$ & UOR $(95 \% \mathrm{CI})$ & AOR $(95 \% \mathrm{CI}$ \\
\hline Hypoxaemic $\left(\mathrm{SpO}_{2}<90 \%\right)^{*}$ & 110 & 17.3 & $4.71(2.16,10.27)$ & $7.54(2.80,20.29)$ \\
Acidosis & 57 & 21.1 & $4.36(1.97,9.65)$ & $6.21(2.21,17.47)$ \\
Hypoglycaemia & 12 & 58.3 & $20.33(5.99,69.07)$ & $19.71(2.61,25.47)$ \\
Pneumonia & 6 & 33.3 & $5.98(1.05,34.10)$ & $19.27(2.87,29.59)$ \\
Hyperparasitaemia & 25 & 20.0 & $3.14(1.09,9.07)$ & $2.21(0.91,8.18)$ \\
Haemoglobinuria & 4 & 75.0 & $37.55(3.78,57.41)$ & $11.63(0.61,92.74)$ \\
Severe malarial anaemia & 201 & 4.0 & $3.64(1.57,8.39)$ & $3.25(0.66,47.63)$ \\
Cerebral malaria & 81 & 14.8 & $2.61(1.20,5.67)$ & $1.84(0.27,2.53)$ \\
Azotaemia & 81 & 13.6 & $2.23(1.01,4.89)$ & $0.62(0.19,2.03)$ \\
Others severe malaria & 87 & 11.5 & $1.70(0.76,3.79)$ & - \\
Male gender & 221 & 8.6 & $1.17(0.54,2.54))$ & - \\
Wasting** & 140 & 14.3 & $2.01(0.43,9.13)$ & - \\
Hypokalaemia & 18 & 11.1 & $1.44(0.32,6.59)$ & - \\
Hyponatraemia & 32 & 12.5 & $1.71(0.56,5.25)$ & - \\
Renal impairment & 3 & 33.3 & $3.90(0.39,38.66)$ & - \\
\hline
\end{tabular}

*All received oxygen therapy $\quad * *$ Weight-for-height, Z-score $<2.0$; UOR: Unadjusted Odds Ratio, AOR: Adjusted Odds Ratio

The multivariate logistic regression model showed that there were four significant independent predictors of mortality from severe malaria in children, including presence of hypoxaemia $(\mathrm{AOR}=7.54 ; 95 \% \mathrm{CI}=$ 2.80, 20.29, metabolic acidosis (AOR $=6.21,95 \% \mathrm{CI}$ $=2.21,17.47)$, hypoglycaemia $(\mathrm{AOR}=19.71 ; 95 \% \mathrm{CI}$ $=2.61,24.47)$ and pneumonia $(\mathrm{AOR}=19.27 ; 95 \% \mathrm{CI}$ $=2.87,29.59)$, However, univariate analysis showed that children with hyperparasitaemia, haemoglobinuria, SMA, cerebral malaria and azotaemia were more likely to die compared with others but not significantly so after controlling for others factors in the logistic regression model.

\section{Discussion}

This study reveals that hypoxaemia is commonin children with severe falciparum malaria and it is an independent predictor of death. Children with severe malaria who had hypoxaemia on arrival at the emergency unit were seven times more likely to die compared with others irrespective of other clinical or laboratory features. Previous studies among children have emphasised the contribution of hypoxaemia to death mainly in acute respiratory infection ${ }^{22,23}$ and less frequently in malaria infection ${ }^{23}$. The prevalence of hypoxaemia among children with severe falciparum malaria in the current study was $29.8 \%$. This value was considerably higher than $17 \%$ reported by Maitland and colleagues ${ }^{10}$ in a retrospective review of cases of severe falciparum malaria among Kenyan children, the highest prevalence in published literature ${ }^{23}$. The fact that this study was prospective in design and that all children admitted during the study period were screened for hypoxaemia may have systematically increased the chance of detecting hypoxaemia than in such a retrospective study, in which there might not have been adequate documentation. Another reason for the high prevalence of hypoxemia in the present study might be because the study was conducted in a tertiary health facility, which frequently receives more severe cases of malaria. These children are more likely to be hypoxaemic compared to those seen in other health facilities.

There are a few reasons why children with severe malaria could have hypoxaemia. For instance, upper airway obstruction may occur from retained secretions or changes in upper airway tone; apnoea may occur because of chest wall rigidity during convulsions; and pulmonary aspiration or collapse may occur. Coexisting pneumonia is also a likely occurrence in severe malaria and the standard clinical signs of acute lower respiratory tract infection may not be as clear in the setting of cerebral malaria and hypoxia. However, there were only six cases with co-existing pneumonia 
among the patients but $12.7 \%$ had multiple convulsions as part of their presenting features. The coexistence of pneumonia and convulsions are probably not sufficient to explain the magnitude of hypoxaemia found among the study patients.

While previous studies on predictors of mortality have taken little notice of hypoxaemia, the present data have underscored the need to pay more attention to oxygen saturation as a plausible prognostic index in severe malaria illness. A recent study with a large number of African children, in which predictors of deaths due to severe malaria were evaluated, did not report findings on oxygen saturation ${ }^{13}$. The current report is probably the first to prospectively evaluate the effects of hypoxaemia on outcome of admission among children with severe falciparum malaria in Nigeria. Early detection of hypoxaemia and administration of oxygen have been shown to considerably reduce mortality and improves admission outcome in emergency units ${ }^{12,24}$. Findings from present study therefore, highlight the need for providing oxygen for children with severe falciparum malaria in Africa. In the light of the high prevalence of hypoxaemia among severe malaria patients and the scarcity of pulse oximetry in the hospitals, managing these children will rely on the accurate identification of clinical signs of hypoxaemia. However, clinical signs might not sufficiently identify many children needing oxygen therapy. There is the need for policy makers and clinicians to consider the adoption of pulse oximetry to improve the detection of hypoxaemia and monitoring of oxygen saturation in the protocol for case management of severe malaria.

Additionally, this study provides further evidence for acidosis and hypoglycaemia as predictors of poor outcome in children with malaria. Earlier studies have shown that these two factors were good prognostic indicators of poor outcome in severe malaria ${ }^{3,25,26}$. The association between hypoglycaemia and death in this study is however at variance with the report by von Seidlein et al., ${ }^{13}$ in which no association was found. Hypoglycaemia is reversible if detected early, but many of the patients in this study might have presented late such that irreversible tissue damage had occurred. One possible explanation for the high prevalence of acidosis and its adverse effects is that sequestration of red blood cells containing the mature parasites leads to tissue ischaemia and impairment of microcirculatory flow, causing tissue hypoxia and a shift from aerobic to anaerobic metabolism. Consequent to this, there is conversion of pyruvate into lactic acid, which is an important contributor to acidosis in malaria ${ }^{27,28}$.

In this study, respiratory signs were not included in the models for prediction of deaths because they are known to occur in response to acidosis and base deficit. There was no association between severe anaemia and death in this study. This is not surprising as only $4.0 \%$ case fatality was recorded among children with severe malarial anaemia. All cases of severe anaemia were offered blood transfusion as soon as they were admitted, this treatments may have reversed the progression of the adverse effects of low haemoglobin concentration on the patients ${ }^{29}$. Furthermore, this study shows that children with malaria and bacteria co-infections have higher mortality than others. This has been previously documented ${ }^{30-32}$. It is possible that the malaria infection was not the primary cause of the illness, but was instead a coincidental infection. Another factor previously reported but not associated with a poor outcome in severe malaria in this study is hyperparasitaemia ${ }^{33}$. Nonetheless, high parasite densities, above 250,000/ $\mu \mathrm{L}$, had increased risk of death but not independent of other life-threatening features of severe malaria when included in the logistic regression model.

A major strength of this study is the homogeneous nature of the patients. All the children who participated in the study received treatments under the same condition with no significant change of personnel during the study period; they were all Nigerian children and had similar socioeconomic, environmental and ethnic background. These removed, to some extent, inter-observer variability in measurements. However, the geographic restriction and relatively small sample size may limit the generalisability of the study findings to other malaria endemic countries. Another important factor that limits the generalisability of the findings is the fact that the study was conducted within the context of a tertiary health facility. This might have influenced the rates of hypoxaemia reported compared to what could have been obtained among children in primary and secondary health facilities. Therefore, a multicentre study with larger sample size including children from lower levels of healthcare is desirable to confirm the fact that hypoxaemia predicts death in children with malaria irrespective of other life-threatening features.

In conclusion, this study has highlighted the importance of hypoxemia in severe falciparum malaria-associated mortality and stressed the need for pulse oximetry in case management of severe malaria. These findings support the calls for adoption of pulse oximetry for 
improving the detection of hypoxaemia, for making assessment of oxygen saturation a regularly measured vital sign, and for incorporating measurement of $\mathrm{SpO}_{2}$ in the algorithms for categorising malaria severity. The study could also act as a thrust for increasing awareness of hypoxaemia in childhood malaria and in making relevant resources available.

\section{Authors' contributions}

$\mathrm{AEO}$ and BOO designed the research, supervised the care of the children and data collection in the emergency unit. BEO assisted with monitoring and ensured the quality of the laboratory data. AEO carried out the data analysis while $\mathrm{AEO}, \mathrm{BOO}$ and $\mathrm{BEO}$ wrote and read the manuscript. All authors read and approved the final manuscript.

\section{Acknowledgements}

We are grateful to DrShannon Carson of the Pulmonary Diseases \& Critical Care Fellowship Program, University of North Carolina, USA for his mentorship during the 2009 PATS-MECOR training at Kenya when the idea of writing for the small grant award was conceived. We are indebted to all the children and caregivers who participated in the study. We also thank Mr. Emmanuel Oni (research assistant on the project), resident doctors and all nursing staff of the Children Emergency Unit of the University College Hospital, Ibadan for their assistance and cooperation.

\section{Funding}

This research was partly funded with Small Grant Award of the Pan African Thoracic Society Methods in Epidemiologic, Clinical and Operational Research (PATS-MECOR) which is based on the American Thoracic Society (ATS) MECOR program.

Competing interests: The authors hereby declare no competing interests.

\section{References}

1. Watson R. Mortality rates from malaria in children under 5 fall sharply in 10 countries. BMJ2008;336(7657):1331.

2. Murray CJ, Rosenfeld LC, Lim SS, Andrews KG, Foreman KJ, Haring D, Fullman N, Naghavi M, Lozano R, Lopez AD. Global malaria mortality between 1980 and 2010: a systematic analysis. Lancet 2012;379(9814):41331.

3. Ramroth H, Ndugwa RP, Muller O, Ye Y, Sie A,
Kouyate B, Becher H. Decreasing childhood mortality and increasing proportion of malaria deaths in rural Burkina Faso. Glob Health Action 2009;2.

4. Ndugwa RP, Ramroth H, Muller O, Jasseh M, Sie A, Kouyate B, Greenwood B, Becher H. Comparison of all-cause and malaria-specific mortality from two West African countries with different malaria transmission patterns. Malar J 2008;7:15.

5. Federal Ministry of Health. National Guidelines for Diagnosis and Treatment of Malaria. Abuja-Nigeria: Federal Ministry of Health, National Malaria and Vector Control Division, 2011.

6. Olumese PE, Sodeinde O, Gbadegesin RA, Nafiu O, Oguche S, Walker O. Respiratory distress adversely affects the outcome of childhood cerebral malaria. Trans R Soc Trop Med Hyg 1995;89(6):634.

7. Issifou S, Kendjo E, Missinou MA, Matsiegui PB, Dzeing-Ella A, Dissanami FA, Kombila M, Krishna S, Kremsner PG. Differences in presentation of severe malaria in urban and rural Gabon. Am J Trop Med Hyg 2007;77(6):1015-9.

8. English M, Waruiru C, Amukoye E, Murphy S, Crawley J, Mwangi I, Peshu N, Marsh K. Deep breathing in children with severe malaria: indicator of metabolic acidosis and poor outcome. Am J Trop Med Hyg 1996;55(5):521-4.

9. Laman M, Ripa P, Vince J, Tefuarani N. Can clinical signs predict hypoxaemia in Papua New Guinean children with moderate and severe pneumonia? Ann Trop Paediatr 2005;25(1):23-7.

10. Maitland K, Levin M, English M, Mithwani S, Peshu N, Marsh K, Newton CR. Severe P. falciparum malaria in Kenyan children: evidence for hypovolaemia. QJM 2003;96(6):427-34.

11. Mwaniki MK, Nokes DJ, Ignas J, Munywoki P, Ngama M, Newton CR, Maitland K, Berkley JA. Emergency triage assessment for hypoxaemia in neonates and young children in a Kenyan hospital: an observational study. Bull World Health Organ 2009;87(4):263-70.

12. Junge S, Palmer A, Greenwood BM, Kim Mulholland E, Weber MW. The spectrum of hypoxaemia in children admitted to hospital in The Gambia, West Africa. Trop Med Int Health 2006;11(3):367-72.

13. von Seidlein L, Olaosebikan R, Hendriksen IC, Lee SJ, Adedoyin OT, Agbenyega T, Nguah SB, Bojang K, Deen JL, Evans J, Fanello CI, Gomes E, Pedro AJ, Kahabuka C, Karema C, Kivaya E, Maitland K, Mokuolu OA, Mtove G, Mwanga-Amumpaire J, Nadjm B, Nansumba M, Ngum WP, Onyamboko MA, Reyburn H, Sakulthaew T, Silamut K, Tshefu AK, Umulisa N, Gesase S, Day NP, White NJ, Dondorp AM. Predicting the 
clinical outcome of severe falciparum malaria in african children: findings from a large randomized trial. Clin Infect Dis 2012;54(8):1080-90.

14. Duke T, Blaschke AJ, Sialis S, Bonkowsky JL. Hypoxaemia in acute respiratory and non-respiratory illnesses in neonates and children in a developing country. Arch Dis Child 2002;86(2):108-12.

15. United Nations (UN). World Population Prospects: The 2012 Revision Population Division of the United Nations Department of Economic and Social Affairs of the United Nations Secretariat.

16. Orimadegun AE, Ogunbosi BO, Akinbami FO. Knowledge and views of paediatricians about pulse oximetry: a nationwide online survey in Nigeria. African Journal of Respiratory Medicine 2011;7(1):14-18.

17. WHO. Severe falciparum malaria. World Health Organization, Communicable Diseases Cluster. Trans R Soc Trop Med Hyg 2000;94 Suppl 1:S1-90.

18. Ayieko P, English M. In children aged 2-59 months with pneumonia, which clinical signs best predict hypoxaemia? J Trop Pediatr 2006;52(5):307-10.

19. Ayieko P, English M. Case management of childhood pneumonia in developing countries. Pediatr Infect Dis J 2007;26:432-40.

20. Puumalainen T, Quiambao B, Abucejo-Ladesma E, Lupisan S, Heiskanen-Kosma T, Ruutu P, Lucero MG, Nohynek H, Simoes EA, Riley I. Clinical case review: a method to improve identification of true clinical and radiographic pneumonia in children meeting the World Health Organization definition for pneumonia. BMC Infect Dis 2008;8:95.

21. World Health Organization (WHO). Guidelines for the treatment of malaria. 2nd ed. Geneva: WHO, 2010;1-194.

22. Duke T, Mgone J, Frank D. Hypoxaemia in children with severe pneumonia in Papua New Guinea. Int J Tuberc Lung Dis 2001;5(6):511-9.

23. Subhi R, Adamson M, Campbell H, Weber M, Smith $\mathrm{K}$, Duke T. The prevalence of hypoxaemia among ill children in developing countries: a systematic review. Lancet Infect Dis 2009;9(4):219-27.

24. Weber MW, Palmer A, Oparaugo A, Mulholland EK. Comparison of nasal prongs and nasopharyngeal catheter for the delivery of oxygen in children with hy- poxemia because of a lower respiratory tract infection. J Pediatr 1995;127(3):378-83.

25. Krishna S, Waller DW, ter Kuile F, Kwiatkowski D, Crawley J, Craddock CF, Nosten F, Chapman D, Brewster D, Holloway PA, et al. Lactic acidosis and hypoglycaemia in children with severe malaria: pathophysiological and prognostic significance. Trans R Soc Trop Med Hyg 1994;88(1):67-73.

26. Day NP, Phu NH, Mai NT, Chau T'T, Loc PP, Chuong LV, Sinh DX, Holloway P, Hien TT, White NJ. The pathophysiologic and prognostic significance of acidosis in severe adult malaria. Crit Care Med 2000;28(6):1833-40.

27. Vernon C, Letourneau JL. Lactic acidosis: recognition, kinetics, and associated prognosis. Crit Care Clin 2010;26(2):255-83, table of contents.

28. Dondorp AM, Chau TT, Phu NH, Mai NT, Loc PP, Chuong LV, Sinh DX, Taylor A, Hien T'T, White NJ, Day NP. Unidentified acids of strong prognostic significance in severe malaria. Crit Care Med 2004;32(8):1683-8.

29. English M, Ahmed M, Ngando C, Berkley J, Ross A. Blood transfusion for severe anaemia in children in a Kenyan hospital. Lancet 2002;359(9305):494-5.

30. Reyburn H, Mbatia R, Drakeley C, Carneiro I, Mwakasungula E, Mwerinde O, Saganda K, Shao J, Kitua A, Olomi R, Greenwood BM, Whitty CJ. Overdiagnosis of malaria in patients with severe febrile illness in Tanzania: a prospective study. BMJ 2004;329(7476):1212.

31. Nadjm B, Amos B, Mtove G, Ostermann J, Chonya S, Wangai H, Kimera J, Msuya W, Mtei F, Dekker D, Malahiyo R, Olomi R, Crump JA, Whitty CJ, Reyburn $\mathrm{H}$. WHO guidelines for antimicrobial treatment in children admitted to hospital in an area of intense Plasmodium falciparum transmission: prospective study. BMJ 2010;340:c1350.

32. Berkley JA, Lowe BS, Mwangi I, Williams T, Bauni E, Mwarumba S, Ngetsa C, Slack MP, Njenga S, Hart CA, Maitland K, English M, Marsh K, Scott JA. Bacteremia among children admitted to a rural hospital in Kenya. N Engl J Med 2005;352(1):39-47.

33. Molyneux ME, Taylor TE, Wirima JJ, Borgstein A. Clinical features and prognostic indicators in paediatric cerebral malaria: a study of 131 comatose Malawian children. QJ Med 1989;71(265):441-59. 